\title{
MELTING POINTS OF SOME REFRACTORY OXIDES
}

\author{
By C. W. Kanolt
}

A previous paper ${ }^{1}$ dealt with the melting points of commercial refractory materials; the present work is on the melting points of pure oxides. Results obtained with magnesia, lime, alumina, and chromium oxide are given. Although numerous oxides are used as refractory materials, as furnace linings, in the Nernst filament, the Welsbach mantle, and the limelight, and in the laboratory, the melting points of but very few have been known within several hundred degrees. Many of the published determinations are quite uncertain. For example, some determinations would indicate that lime and magnesia are more fusible than alumina, which can easily be demonstrated to be untrue, for alumina is readily fused in the oxyhydrogen flame, while pure lime and pure magnesia are infusible in it, at least under ordinary conditions.

The principal difficulties encountered in the accurate determination of the melting points are the production of very high temperatures uniform over a sufficient space and controllable; the supporting of the oxide in the furnace without its contamination by the material used as a support; the avoidance of smoke, which would interfere with the measurement of temperature by an optical pyrometer; and finally, the accurate measurement of the temperature.

The furnace used was an Arsem graphite resistance furnace, ${ }^{2}$ with some minor modifications. This furnace was designed to be used with a vacuum, which prevents the oxidation of the graphite and diminishes the heat losses. The vacuum has also a great advantage in the measurement of high temperatures, as it prevents the formation of smoke. With the use of the vacuum, the furnace

${ }^{1}$ B. S. Tech. Papers, No. 10, 1912.

2 Arsem: J. Am. Chem. Soc., 28, p. 921, 1906; Trans. Am. Electroch. Soc., 9, p. 150 , 1906. 
is capable of giving temperatures over $3000^{\circ} \mathrm{C}$., but when an attempt was made to melt oxides in a vacuum in this furnace it was found that when the temperature reached about $2200^{\circ}$ there was an electric discharge from the ends of the heater to the graphite shield, which soon amounted to a short circuit. This is probably a phenomenon of the same sort as the Edison effect. It has been shown by Pring and Parker ${ }^{3}$ that the electric discharge from heated carbon is very much less if the carbon is pure than if it contains a small amount of impurity. From this it appears that impurity in the graphite was probably responsible for the discharge in the Arsem furnace. Perhaps the discharge could have been prevented by purifying the graphite of the heater, but as the vaporization of the oxides heated would soon contaminate it again, the procedure would probably be of little use. The discharge can be avoided by using heaters of very low resistance, making it possible to introduce the requisite power at a very low voltage, but this has other disadvantages. The discharge can also be avoided by working at atmospheric pressure, with the concomitant difficulty of the presence of smoke. This procedure was found to be necessary in many cases, for when lime and magnesia are heated in a vacuum they vaporize completely before the melting point is reached.

With the use of atmospheric pressure considerably more power is required to reach the same temperature, and as the supply of power available was limited it was necessary to change the construction of the furnace somewhat before the higher melting points could be reached. The heater was made of somewhat smaller diameter, as shown at E, Fig. I, and a second shield for heat insulation, F, was placed within the shield $G$, supplied with the furnace. The inner shield was filled with powdered graphite, while the outer shield, which of course does not reach so high a temperature, was filled with powdered shrunk magnesia. After this arrangement had been used for some time it was found that the outer shield was badly cracked, apparently as the result of the expansion of the magnesia.

A glass window, $\mathrm{H}$, was substituted for the mica window supplied with the furnace. The glass was attached by a mixture of 


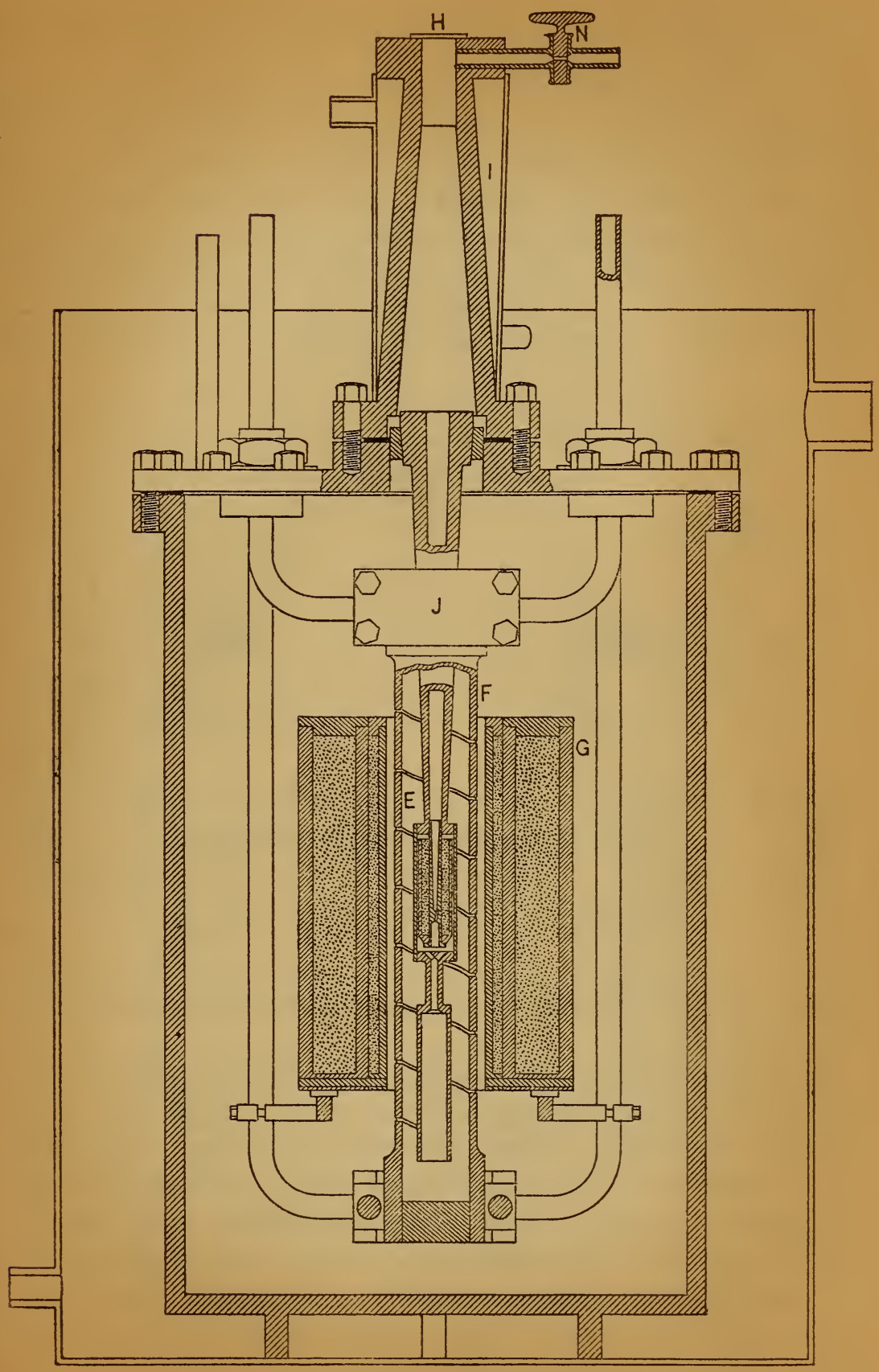

Fig. 1 
rosin and beeswax. To keep this material cool an additional water jacket, I, was applied.

A small improvement in the upper copper clamp, J, connecting the heater with one of the copper tubes carrying the electric current and the cooling water, may be worthy of mention. As originally constructed, only one-half of this clamp was water-cooled directly, the other half being connected to it only by steel screws. This uncooled half is likely to be melted when the furnace temperature is high. To avoid this a clamp of the form shown in Fig. 2 was used. In this, the part $\mathrm{K}$ is kept cool by the conduction

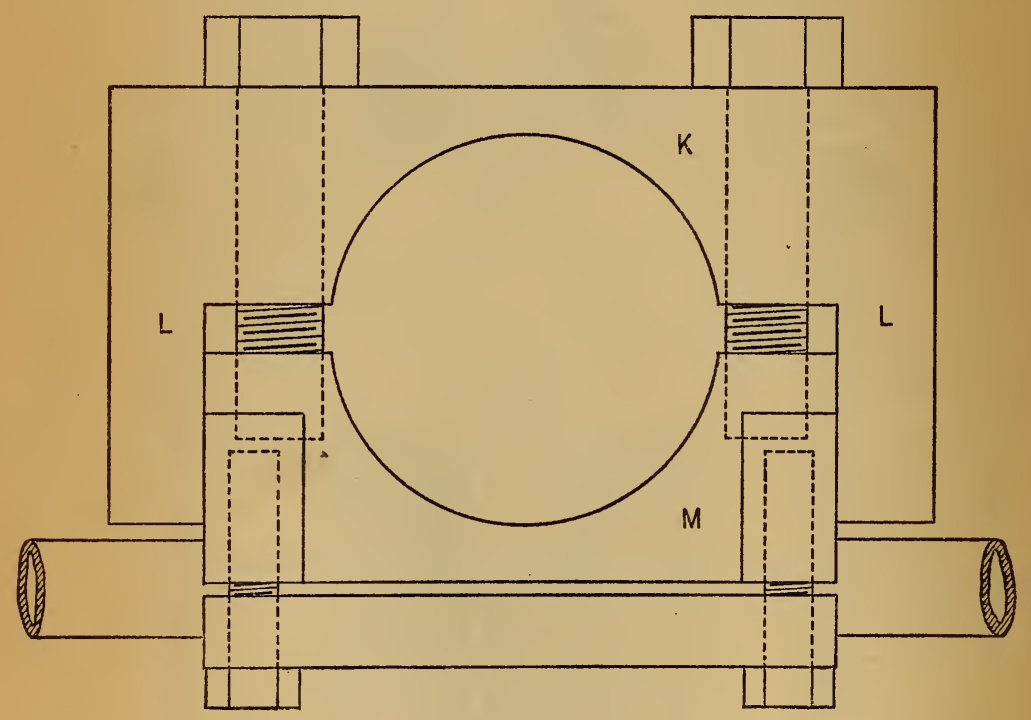

Fig. 2

of heat along the side pieces $\mathrm{L}, \mathrm{L}$, which fit closely upon the watercooled half $\mathrm{M}$.

The temperatures were measured by means of a Morse optical pyrometer of the Holborn-Kurlbaum type, ${ }^{4}$ which was sighted vertically downward through the furnace window. The current in the pyrometer lamp was measured with a Siemens and Halske milliammeter with a shunt. This instrument was calibrated several times, with close agreement, and its very small temperature coefficient was taken into account. Its readings are certainly

4 Holborn and Kurlbaum: Sitzber. d. k. Akad. d. Wissensch. zu Berlin, June 13, p. 712, 1901; Ann. d. Phys., 10, p. 225, 1902. Waidner and Burgess: B. S. Reprint No. 11, 1904. Mendenhall: Phys. Rev.,23, p. 74; 1911. Henning: Zs. 1. Instrumentenkunde, 30, p. 61, 1910. 
reliable to 0.001 ampere and probably to 0.0005 ampere. The pyrometer lamps had been thoroughly aged and were calibrated against the following melting points:

\begin{tabular}{|c|c|}
\hline Material & $\begin{array}{l}\text { Melting } \\
\text { point }\end{array}$ \\
\hline Antimong................................... & ${ }^{\circ} \mathrm{C}$. \\
\hline Copper-silver eutectic.......................... & 779 \\
\hline 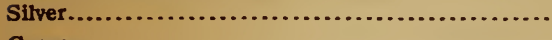 & 960.5 \\
\hline Copper.................................. & 1083 \\
\hline 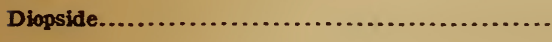 & 1391 \\
\hline
\end{tabular}

These materials were melted in the Arsem furnace in graphite crucibles, similar to that shown in Fig. 3, but entirely closed at the top to prevent contamination. Heating or cooling curves were plotted. This method has already been described. ${ }^{5}$

In the present work some crucibles were used in which the inner tube was enlarged at the bottom in order to form a better black body, but no difference could be detected between the results obtained with this form and with a cylindrical tube.

Diopside has been added to the list of materials previously used in order to make the calibration at the highest temperatures more reliable. There are very few materials melting between the melting point of copper and the working limit of the pyrometer lamps, the melting points of which have been accurately determined. The melting point of diopside is very near this working limit. It has been determined by Day and Sosman. ${ }^{6}$ The sample of diopside used was kindly furnished by Dr. Sosman. Since it is not desirable to use plati-

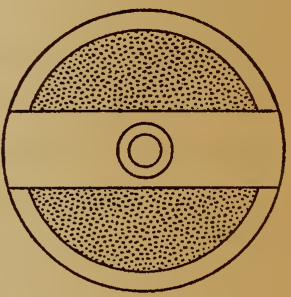
num crucibles in the Arsem furnace, the diopside was melted in Acheson graphite. This has no observable action upon diopside at its melting point. As a check upon this some diopside was maintained near its melting point in a graphite 
crucible for about four hours, while a series of determinations of the melting point was made. No change in the melting point could be detected. A change of $\mathrm{I}^{\circ}$ would probably have been observable. After the pyrometer lamps, which had previously been calibrated at the lower temperatures, had been calibrated at the diopside point, recalibration at lower temperatures lead to the suspicion that they had been changed by the high temperature, although the change was small. To avoid uncertainty from this cause the lamps were completely recalibrated at the four lower points after calibration at the diopside point. Thereafter they were never heated above $1300^{\circ}$.

The relation between pyrometer lamp current and temperature was expressed by an equation of the form, $C=a+b t+c t^{2}$, which could be made to coincide closely with all five points of calibration.

As the temperatures to be measured were far above the working limit of the pyrometer lamps, it was necessary to interpose absorption glasses between the pyrometer and the furnace. In order to calibrate these glasses a graphite crucible was placed in the Arsem furnace, the interior of the crucible forming a field of very uniform brightness. A steady current was passed through the furnace and the temperature allowed to become stationary. Measurements of the apparent temperature were then made alternately with and without the interposition of the absorption glass or combination of glasses to be calibrated. If $T_{1}$ is the absolute temperature as observed without the glass, and $T_{2}$ is the apparent absolute temperature observed with the glass, the following relation is easily deduced from the Wien radiation law:

$$
\frac{\mathrm{I}}{T_{2}}-\frac{\mathrm{I}}{T_{1}}=A
$$

where $A$ is a constant for monochromatic light. The values of the constants of Wien's law do not enter into the work. The difference between the Wien radiation law and the Planck law in the visible spectrum is entirely insignificant.

In some cases a single absorption glass was used; at the highest temperatures it was necessary to use two. The values of $A$ for two or more glasses in series should be equal to the sum of the values for the individual glasses. Theoretically, the double reflections between the surfaces of the different absorption glasses, and 
also between the absorption glasses and the furnace window, should cause a variation from this relation, but it was found by calculation that for the particular combinations used the net result of these small effects was quite negligible. However, the first calibrations of two glasses in series gave values of $A$ somewhat less than the sum of the values for the individual glasses. Similar discrepancies were obtained by Waidner and Burgess ${ }^{7}$ in their work on the temperature of the arc. Such results may be caused by the use of light which is not monochromatic. In the present work the newer kind of Jena red glass, No. 45 I2, was used, and this has so narrow a transmission band that the error from this source can not be large. Calibrations made with Jena red glass No. 2945, which is less nearly monochromatic, gave greater discrepancies. The cause of the discrepancies remaining when the better red glass was used was found in the lag of the pyrometer lamps. These lamps, which were furnished by the makers of the pyrometer, have filaments about $0.17 \mathrm{~mm}$. in diameter and measuring $5 \mathrm{~mm}$. in length of loop, or ro mm. in total length. With such short filaments several minutes are required for the lamp to approach sufficiently near to temperature equilibrium for the most accurate work. This is because with short filaments a considerable proportion of the heat is lost by conduction along the leads, and the temperature of the lamp does not become stationary until temperature equilibrium has been reached in the leads. With lamps having longer filaments a greater proportion of the heat is lost by radiation and the lag is much less. The lag made no considerable difference in the calibration of the lamps, for in this case the lamps were maintained at or near the temperature of the fixed point long enough for equilibrium to be reached. But in the calibration of the absorption glasses by the method first used, it was necessary to change the lamp temperature at frequent intervals, the amount of the change being greatest with dense absorption glasses. To avoid this difficulty two pyrometer lamps were used, each having its own regulating resistance, but so arranged that they could be quickly interchanged in the pyrometer, and could be alternately put in series with the same ammeter. Each lamp was maintained at approximately constant temperature, one being used to measure the temperature of the furnace, the other to meas-

7. S. Reprint No. 8, p. 116; 1904.

$27647^{\circ}-14-10$ 
ure the apparent temperature observed through the absorption glasses. With the use of this apparatus good agreement was obtained between the observed values of $A$ for two absorption glasses in series, and the values calculated from the values for the individual glasses, the remaining discrepancy being such as could be produced by errors of less than ${ }^{\circ}{ }^{\circ}$ in temperature measurement.

The glass furnace window absorbed and reflected a small amount of light, and it was necessary to apply a correction for this. To determine the value of $A$ for the window, a second glass was cut from the same piece, and determinations of the apparent furnace temperature were made alternately with and without the interposition of this second piece. A very small correction was applied for the double reflection between the two pieces.

As a check upon the whole pyrometric apparatus a series of determinations of the melting point of platinum was made. The platinum was melted in tubes made of a mixture of magnesia and alumina, ${ }^{8}$ obtained from the Königliche Porzellan-Manufactur, Berlin. These tubes were inserted in a vertical iridium furnace. Both heating and cooling curves were obtained. The black-body conditions were very good, the platinum being entirely invisible. Usually 3 to 4 grams of platinum were used. The platinum was the purest obtainable from Heraeus, and of the same kind as that used by several investigators in the determination of the melting point of platinum. ${ }^{\circ}$

The results are included in Table $\mathrm{I}$. The weighted mean, $1755^{\circ}$, is identical with the value accepted as the melting point by the Bureau of Standards.

TABLE 1

Melting Point of Platinum

\begin{tabular}{|c|c|c|c|}
\hline Pyrometer lamp & $\begin{array}{l}\text { Absorption } \\
\text { glasses }\end{array}$ & $\underset{\text { point }}{\text { Melting }}$ & Weight \\
\hline $171 \ldots \ldots \ldots \ldots \ldots \ldots \ldots$ & 4248A1 & $\begin{array}{l}{ }^{\circ} \mathrm{C} \\
1745\end{array}$ & 1 \\
\hline $171 \ldots \ldots \ldots \ldots \ldots \ldots \ldots \ldots \ldots \ldots \ldots \ldots \ldots$ & 4248A1 & 1751 & 3 \\
\hline 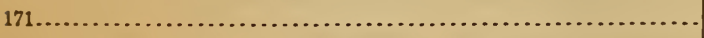 & 4248A1 & 1753 & 3 \\
\hline 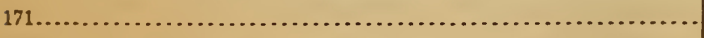 & $4248 \mathrm{~A} 1+4247 \mathrm{~B}$ & 1761 & 3 \\
\hline 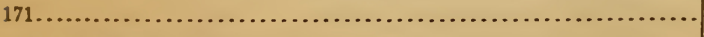 & $4248 \mathrm{~A} 1+4247 \mathrm{~B}$ & 1759 & 3 \\
\hline Weighted mean................ & & 1755 & \\
\hline 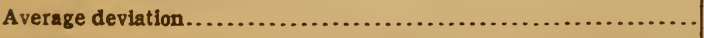 & ......... & 5 & \\
\hline
\end{tabular}

8 Heinecke: Zs. angew. Ch., 21, p. 687; 1908.

' Cl. Waidner and Burgess, B. S. Reprint No. 55, p. 183; 1907. 
The problem of avoiding smoke when the oxides are not heated in a vacuum has received very little attention in previous work, and is probably responsible for several low results. It was found that errors from the presence of smoke could be avoided by introducing into the oxide to be melted a tube of suitable material into which the pyrometer was sighted, and driving from this tube any smoke that might enter through pores or joints by a gentle current of gas. Very good black-body conditions were obtained within such tubes. With this apparatus it was impossible to see the oxide while it was in the furnace, but as all melting points were determined by heating curves this was not necessary, and the determinations could be checked by the examination of samples that had been heated to temperatures slightly below that obtained for the melting point, and also of samples heated slightly above this temperature. A somewhat different method has also been used in determining the melting point of lime. The lime itself was made into a tube, the upper end, by which it was supported, being at a low temperature, while the lower end extended into the hot part of the furnace. The tube was kept free from smoke by a gentle current of hydrogen, which passed out through an oblique opening at the bottom. The pyrometer was sighted into the tube, and a heating curve was plotted. This method has the advantage of avoiding all contact of foreign substances with the material being melted. It is believed that it will prove of value in work upon other substances.

The magnesia used was obtained from the J. T. Baker Chemical Co. The maker's analysis is as follows:

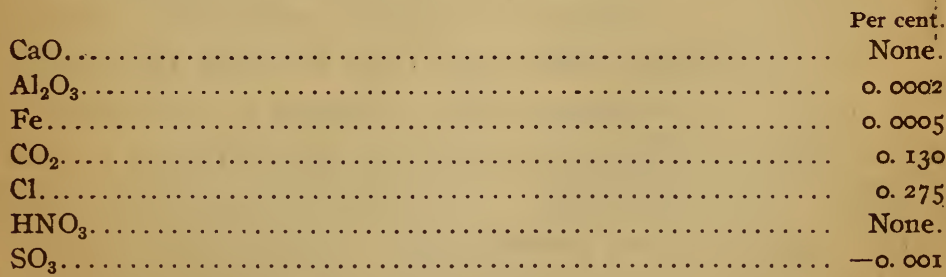

As it is difficult to completely free magnesia from lime, and as it was found that magnesia sold as free from lime may contain considerable quantities of it, a spectroscopic test for lime was made on this sample, but none was found. It was found by experiment 
that the test was sensitive at least to o.or per cent of lime. The carbon dioxide, chlorine, and sulphur trioxide indicated in the maker's analysis would of course be vaporized before the magnesia reached its melting point.

The magnesia was melted in graphite crucibles, for it forms no carbide at high temperature. ${ }^{10}$ It is probably the only refractory

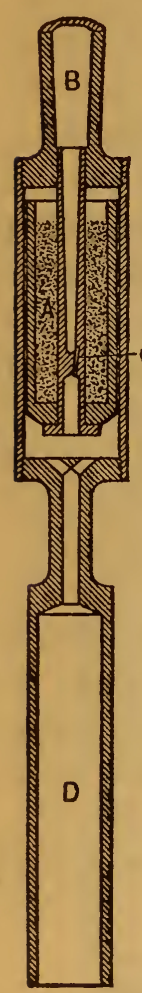

Fig. 4 oxide having this property. It does react with carbon with the formation of carbon monoxide and magnesium vapor, ${ }^{11}$ but this introduces no contamination into the magnesia. It causes a rapid loss of magnesia, especially after fusion, but it was found possible to heat the furnace rapidly enough to determine the melting point before the magnesia had all gone, although it was not practicable to obtain cooling curves, and there was often no magnesia left when the furnace had cooled. All experiments were made at atmospheric pressure in a mixture of carbon monoxide and nitrogen obtained by drawing air through a bed of hot charcoal. When a vacuum was tried the magnesia vaporized before the melting point was reached, even when the magnesia was not heated in contact with carbon, but was in the form of a rod supported by one end which was at a low temperature.

The apparatus used for magnesia is shown in detail in Fig. 4 , and is shown in position in the furnace in Fig. $x$. It was made entirely of graphite. The magnesia is shown at $\mathrm{A}$. The pyrometer was sighted down the tube B. A mixture of carbon monoxide and nitrogen was introduced into this tube through the stopcock $\mathrm{N}$ (Fig. I), and passed down through a very small hole $\mathrm{C}$, which was drilled obliquely to avoid its appearing as a dark spot in the field of the pyrometer. The gas, together with the smoke from the magnesia, then passed down through the tube $D$. The object of this tube was to prevent the gases from coming directly in contact with the hot part of the heater, as this would burn a thin place in the heater. With the use of this apparatus one heater would last for about four experiments, barring accidents. The 
upper part of the tube D was made small to diminish heat conduction; the lower part was made larger to avoid clogging with magnesia. Gas was driven through the apparatus at the rate of about 5 cc per second, measured cold, or about 50 cc per second at the temperature of the apparatus. In order to determine whether this produced an appreciable cooling effect, the empty apparatus was heated to about $2500^{\circ}$ and the temperature allowed to become constant. As there was no magnesia in the furnace there was no perceptible smoke. A number of temperature measurements were then made without a gas current, then with the gas turned on, and again with the gas turned off. The measurements were in close agreement and indicated that the cooling produced was not more than $5^{\circ}$. A confirmation of this was obtained in another way in the work on alumina.

The magnesia that had been fused was colorless, fairly transparent, and of a compact crystalline structure.

The results obtained with magnesia are given in Table 2 .

TABLE 2

Melting point of magnesia, obtained with apparatus shown in Fig. 4

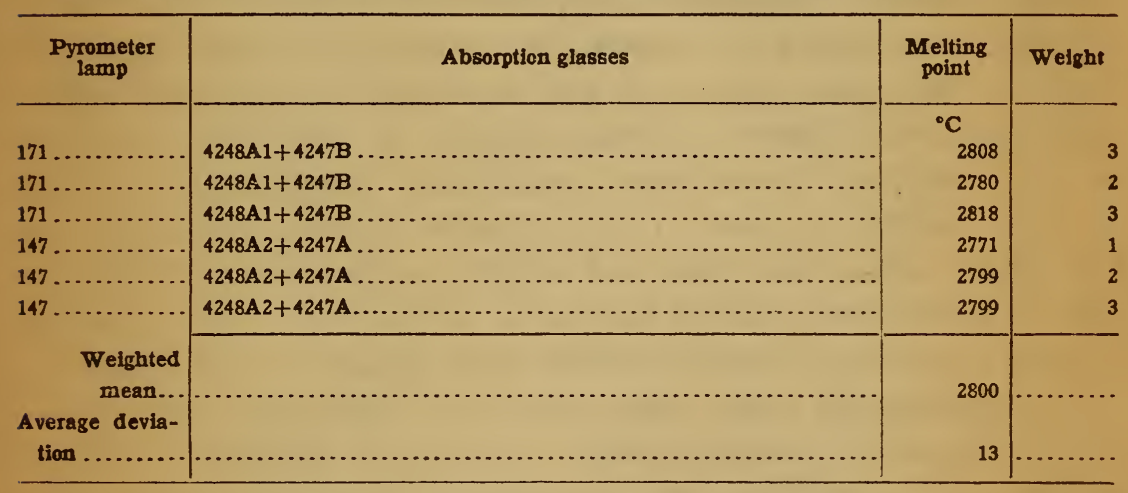

The lime used was obtained by the ignition of some calcium carbonate, obtained from the Baker \& Adamson Chemical Co. The maker's analysis is as follows:

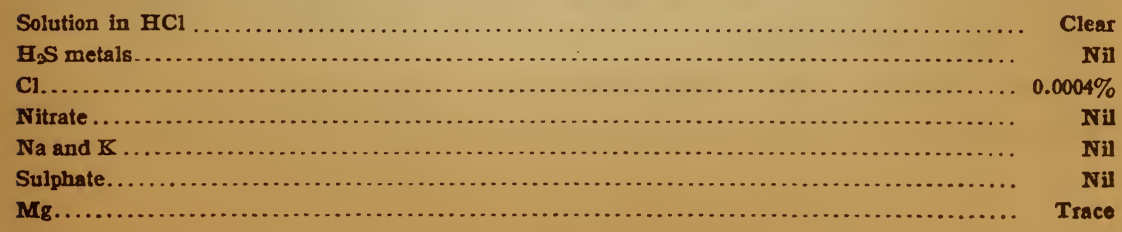


Since lime readily forms carbide when heated to high temperatures in contact with graphite, the use of graphite crucibles, as with magnesia, was out of the question. In place of graphite tungsten was tried. Tungsten is readily obtainable in the form of a fine powder. It is possible to make rods or thick-walled crucibles of this by moistening it with water, compressing it in a mold, and then removing it from the mold and heating it to about $1800^{\circ} \mathrm{C}$ or higher without contact with air. At this temperature the tungsten powder sinters to a porous mass, the hardness of which depends upon the temperature to which it has been heated. But if thin-walled or comparatively frail forms are molded, it is practically impossible to remove them from the mold before heating without breaking or distorting them. This difficulty may be overcome by using a mold the outer parts of which are made of graphite, while the inner parts, by which the inner surfaces of tubes or crucibles are formed, are made of metal: These inner parts are readily removed from the tungsten. The graphite part of the mold and the tungsten in it are then heated together to $1800^{\circ}$ to $2000^{\circ}$, after which the tungsten can be removed from the mold. Tungsten readily combines with carbon at these temperatures, and if the heating is continued for any length of time the tungsten adheres to the mold and may become badly contaminated. However, if the tungsten is heated very rapidly to the sintering temperature and then immediately cooled, as can readily be done in the Arsem furnace, it takes up but little carbon and does not adhere to the mold. Tungsten can be molded into almost any shape in this way. The product is very porous and readily absorbs thin liquids, which would be a disadvantage for many purposes; but it does little harm in the determination of melting points, for after a material has been melted and its melting point determined, it usually matters but little what happens to the melted material. If the tungsten is sintered at a comparatively low temperature it can afterwards be shaped by grinding and to some extent by cutting, although it soon dulls a steel tool.

Three melting-point determinations were made in an apparatus similar to that used for magnesia (Fig. 4), but having the 
crucible and the inner tube made of tungsten. These results were in excellent agreement. The tungsten parts usually melted as soon as the lime melted. This may have been the result in part of the contamination of the tungsten by carbon or the presence of other impurity, but it was noticed that the melting of the crucible appeared to begin on the inside, indicating that it was the result of the contact of tungsten with fused lime. This suggested that if the lime contaminated the tungsten, the tungsten might also contaminate the lime and change its melting point. In order to check the results so obtained the lime tube method was used. This apparatus is shown in Fig. 5.

The lime tube $O$ is connected by a taper joint to the graphite tube $P$, which is supported from the top of the furnace. The hydrogen driven into the tube to remove smoke passes out through the small oblique opening $Q$. It is quite likely that the gas current produced some cooling in this case, for lime is a poorer conductor of heat than the graphite or tungsten used in the inner tubes in previous experiments. This cooling could cause no error in this case, as it is produced directly in the material to be melted. A gentle gas current was found to remove smoke quite effectively. The results obtained in this way agreed entirely with those obtained in tungsten crucibles. A test for calcium

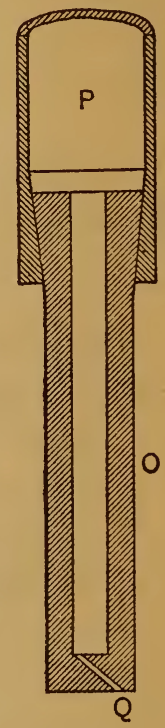

Fig. 5 carbide was applied to lime from the lower end of a lime tube after it had been heated almost to the melting point, but no carbide could be detected. The test was probably sensitive to o.or per cent. This lime was perfectly white. The upper parts of the tubes, which did not reach so high temperatures, were always gray after heating and contained small amounts of carbide. It is probable that at the temperature of fusion any carbide that was formed at lower temperatures reacted with the lime forming carbon monoxide and calcium vapor.

The results obtained with lime are given in Table 3 . 
TABLE 3

Melting Point of Lime

\begin{tabular}{|c|c|c|c|c|}
\hline $\begin{array}{l}\text { Pyrometer } \\
\text { lamp }\end{array}$ & Absorption glasses & Melting apparatus & $\begin{array}{c}\text { Melting } \\
\text { point }\end{array}$ & Weight \\
\hline $171 \ldots$ & $4248 \mathrm{~A} 1+4247 \mathrm{~B}$ & Fig. 4 (tungsten). & $\begin{array}{l}\text { Deg. } \\
2565\end{array}$ & \\
\hline $171 \ldots \ldots$ & $4248 \mathrm{~A} 1+4247 \mathrm{~B}$ & ...... do $\ldots \ldots \ldots$ & 2575 & 1 \\
\hline $171 \ldots \ldots$ & $4248 \mathrm{~A} 1+4247 \mathrm{~B}$ & $\ldots$ do $\ldots \ldots \ldots$ & 2575 & 1 \\
\hline $171 \ldots$ & $4248 \mathrm{~A} 1+4247 \mathrm{~B}$ & Fig. $5 \ldots$ & 2571 & 3 \\
\hline $171 \ldots$ & $4248 \mathrm{~A} 2+4247 \mathrm{~A}$ & ......do ...... & 2572 & 3 \\
\hline $171 \ldots \ldots \ldots \ldots$ & $4248 \mathrm{~A} 2+4247 \mathrm{~A}$ & $\ldots$. do $\ldots \ldots \ldots$ & 2575 & 2 \\
\hline $\begin{array}{l}\text { Weighted } \\
\text { mean. }\end{array}$ & & & 2572 & \\
\hline $\begin{array}{l}\text { Average devia- } \\
\text { tion. }\end{array}$ & & & & \\
\hline
\end{tabular}

The alumina used was obtained from Eimer \& Amend. The. maker's analysis is as follows:

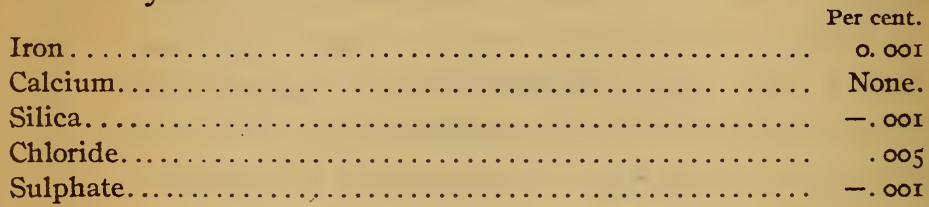

The first determinations of its melting point, made before the tungsten crucibles had been prepared, were made in graphite. Alumina forms a carbide at its melting point, but the reaction is not a rapid one. There appeared to be none formed until after the alumina had melted and had remained for a time in contact with carbon. The alumina rapidly diminished in quantity after melting. How much of this loss was the result of the vaporization of alumina and how much the result of reaction with the graphite with the formation of aluminum vapor was not determined. Alumina that had remained in the melted condition but a short time was white and of a compact crystalline structure. When maintained in a fused condition for some time it became grayish in color. Any changes that may occur after the fusion of the alumina cause, of course, no error in the melting-point determination. After tungsten crucibles had been prepared determinations were made in tungsten with the same results. Alumina can be melted in a vacuum sufficiently good to prevent smoke without 
vaporizing too rapidly. Experiments were made at a pressure of about $2 \mathrm{~mm}$ of mercury and also at atmospheric pressure. In the latter case apparatus of the form used with magnesia (Fig. 4) was used. In working with a vacuum, crucibles of the form shown in Fig. 3 were used. As these crucibles were partly open at the top the melting material could be seen at the same time that the temperature determinations were made with the pyrometer sighted down the inner tube. The close agreement between results obtained in a vacuum and at atmospheric pressure in a current of gas is further evidence that the gas current does not cool the inner tube appreciably.

The results obtained with alumina are given in Table 4 .

TABLE 4

Melting Point of Alumina

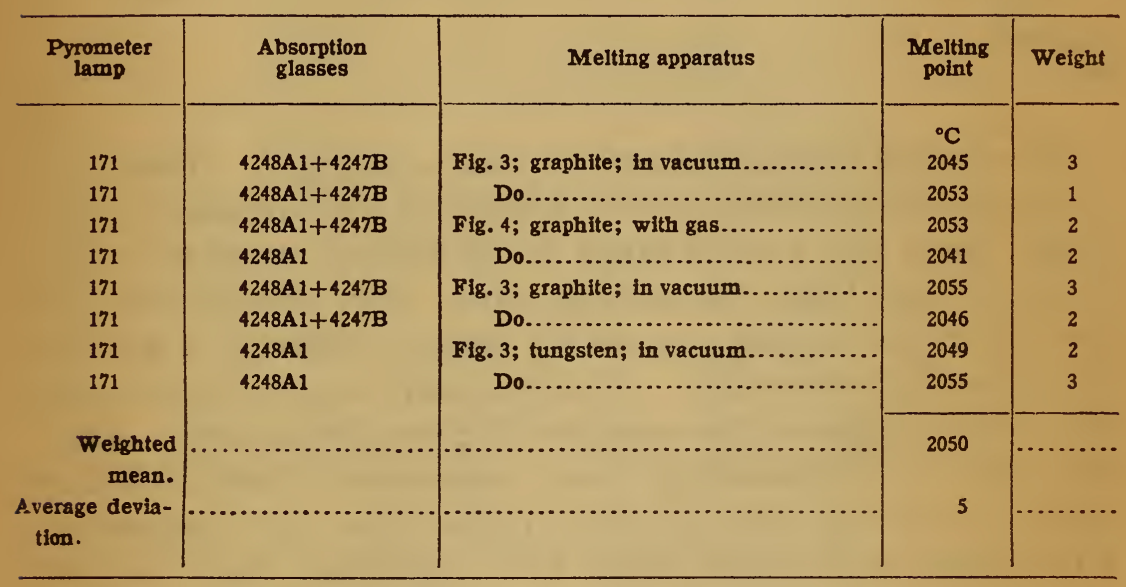

The chromium oxide $\left(\mathrm{Cr}_{2} \mathrm{O}_{3}\right)$ used was obtained from Eimer \& Amend. The maker's analysis is as follows:

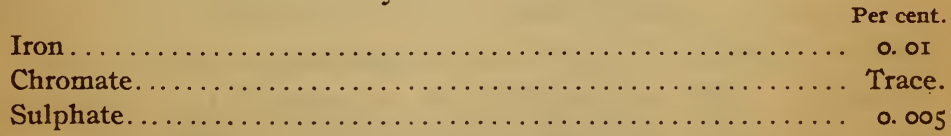

It was melted in a vacuum in crucibles of the form shown in Fig. 3. When graphite crucibles were used there was little reduction until the oxide began to melt; then there was a vigorous reaction. When tungsten crucibles were used the melted oxide 
soaked into the porous tungsten to a considerable extent. The results obtained with the two crucible materials were in agreement. They are given in Table 5 .

\section{TABLE 5}

Melting point of chromium oxide, obtained with crucibles of the form shown in Fig. 3

\begin{tabular}{|c|c|c|c|c|}
\hline $\begin{array}{l}\text { Pyrometer } \\
\text { lamp }\end{array}$ & Absorption glasses & Crucible material & $\begin{array}{c}\text { Melting } \\
\text { point }\end{array}$ & Weight \\
\hline $171 .$. & $4248 \mathrm{~A} 1+4247 \mathrm{~B}$ & Graphite.. & ${ }^{\circ} \mathrm{C}$ & \\
\hline $171 .$. & $4248 A 1+4247 B .$. & Tungsten $\ldots . . . \ldots \ldots \ldots \ldots$ & 1982 & \\
\hline 171.. & $4248 \mathrm{~A} 1+4247 \mathrm{~B} \ldots \ldots$ & ...do... & 1979 & \\
\hline $171 .$. & $4248 \mathrm{~A} 1 \ldots \ldots \ldots \ldots$. & Graphite ..................... & 1991 & 1 \\
\hline $171 .$. & $4248 A 2 \ldots \ldots \ldots \ldots \ldots$ & Tungsten ..................... & 2000 & 3 \\
\hline $\begin{array}{c}\text { Weighted } \\
\text { mean. }\end{array}$ & & & 1990 & \\
\hline $\begin{array}{l}\text { Average devia- } \\
\text { tion. }\end{array}$ & & & 6 & \\
\hline
\end{tabular}

Some typical heating curves are shown in Fig. 6. There was no appreciable difference in curves obtained with different oxides. Usually there was a small break in the heating curve at a temperature a little below the melting point. It is believed that this small lag in the heating was always present, although it was not always certainly observable. It undoubtedly occurs at the instant that melting begins on the outside of the mass of material. Since the oxides are comparatively poor conductors of heat and since the rate of heating was necessarily rather rapid, the temperature of the inside of the mass where the temperature was measured lagged appreciably behind the temperature of the outside, until the outside began to melt, after which the temperature of the inside rose to the melting temperature already reached on the outside, and a distinct break in the curve corresponding to the true melting point followed. This explanation is supported by observations made when the open crucibles shown in Fig. 3 were used. The beginning of melting on the outside of the mass was sometimes observed at the same time that the small preliminary break in the heating curve occurred. 
In Table 6, the results obtained are compared with determinations by previous investigators. It will be noted that the older values for the melting points of magnesia and lime are very much

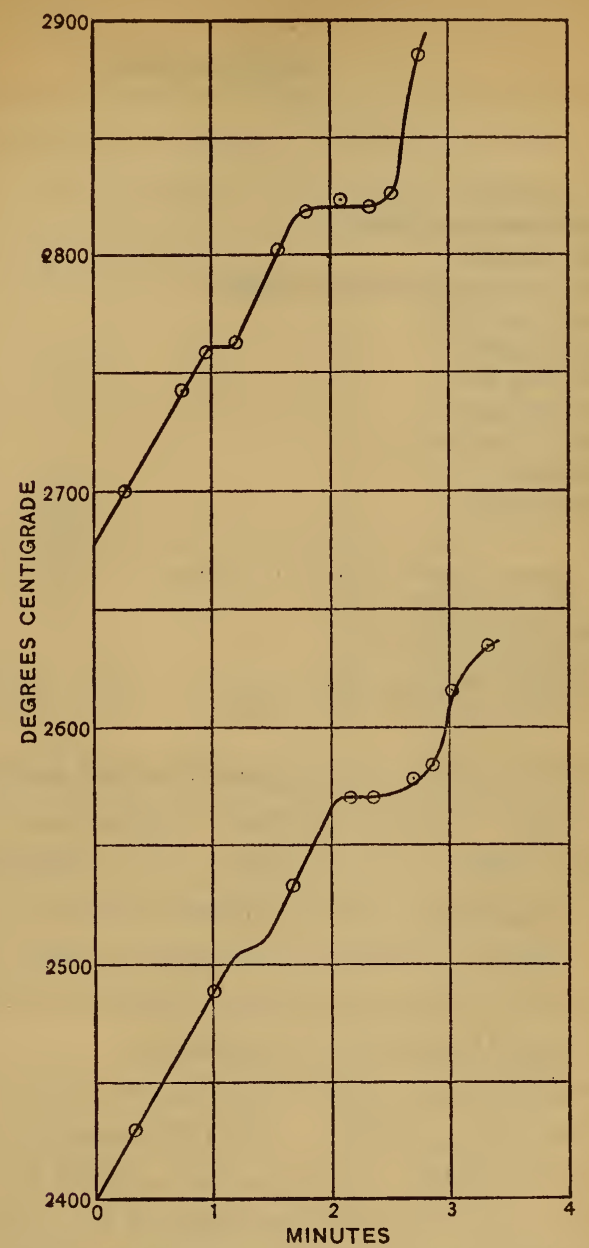

Fig. 6. - Heating curves obtained with magnesia (upper curve) and lime (lower curve).

lower than the results of this investigation, although Greenwood ${ }^{12}$ records the use of magnesia crucibles as high as $2500^{\circ}$. In the work of Hempel, Goodwin and Mailey, and Lampen there seems 
to have been little or no precaution taken against the presence of smoke.

\section{TABLE 6}

\begin{tabular}{|c|c|c|}
\hline Material & $\begin{array}{l}\text { Melting } \\
\text { point, Bu- } \\
\text { reau of } \\
\text { Standards }\end{array}$ & Previous determinations \\
\hline \multirow{5}{*}{ MgO....... } & ${ }^{\circ} \mathrm{C}$. & 2250 Hempel 13 \\
\hline & & 1910 Goodwin and Mailey 14 \\
\hline & & 2000 Lampen 15 \\
\hline & & 1980-2023 Mendenhall and Ingersoll 16 \\
\hline & & Over 2500 Ruff 17 \\
\hline \multirow[t]{2}{*}{$\mathrm{CaO}$} & 2572 & 1900 Hempel 13 \\
\hline & & Over 2450 Ruff 17 \\
\hline \multirow[t]{3}{*}{$\mathrm{Al}_{2} \mathrm{O}_{3}}$. & 2050 & 1800 Hempel $^{13}$ \\
\hline & & 2050-2100 Saunders 18 \\
\hline & & 2010 Ruff 17 \\
\hline $\mathrm{C}_{r_{2}} \mathrm{O}_{3}$ & 1990 & 2060-2080 Ruff 17 \\
\hline
\end{tabular}

${ }^{13}$ Ber. Inter. Kongress Angew. Chem., 1, p, 715; 1903.

14 Phys. Rev., 23, p. 22; 1906.

${ }^{15} \mathrm{~J}$. Am. Chem. Soc., 28, p. 846; 1906.

16 Phys. Rev., 25, p. I; 1907.

${ }^{17} \mathrm{Zs}$. f. anorg. Chem., 82, p. 373; 1913.

${ }_{18}$ Trans. Am. Electrochem. Soc., 19, p. 333; 1911.

In the work of Mendenhall and Ingersoll small particles of magnesia were heated upon a Nernst glower. On account of the small amount of material there was probably no considerable amount of smoke, but the magnesia would almost certainly flux with the glower material. None of these investigators have given much attention to the purity of the magnesia, which seems to be more difficult to obtain pure than lime or alumina.

Ruff and his collaborators have published determinations of a large number of melting points. The full results have appeared since this article was written. The value quoted above for chromium oxide $\left(2060\right.$ to $\left.2080^{\circ}\right)$ is not presented by Ruff as the true melting point. Lower values were also obtained but were apparently the result of partial reduction.

The writer has obtained preliminary results with other oxides and the work will probably be extended. The method in which the refractory material is made into a tube appears to be the most promising.

Mr. S. E. Moore has rendered valuable assistance in this work. 


\section{SUMMARY}

The melting points of some refractory oxides have been determined in a graphite resistance vacuum furnace. The temperatures were measured by an optical pyrometer and heating curves were plotted. The production of smoke when some of the oxides were heated was found to be an important source of error, as the smoke interferes with the use of the pyrometer. Means by which this difficulty was overcome are described. The following melting points were obtained, the melting point of platinum being determined merely as a check.

\begin{tabular}{l|c}
\hline Material & Melting point \\
\hline & ${ }^{\circ} \mathrm{C}$. \\
$\mathrm{MgO}$ & 2800 \\
$\mathrm{CaO}$ & 2572 \\
$\mathrm{Al}_{3} \mathrm{O}_{3}$ & 2050 \\
$\mathrm{Cr}_{3} \mathrm{O}_{3}$ & 1990 \\
$\mathrm{Pt}$ & 1775 \\
\hline
\end{tabular}

WASHINGTON, Junè I, I9r3. 


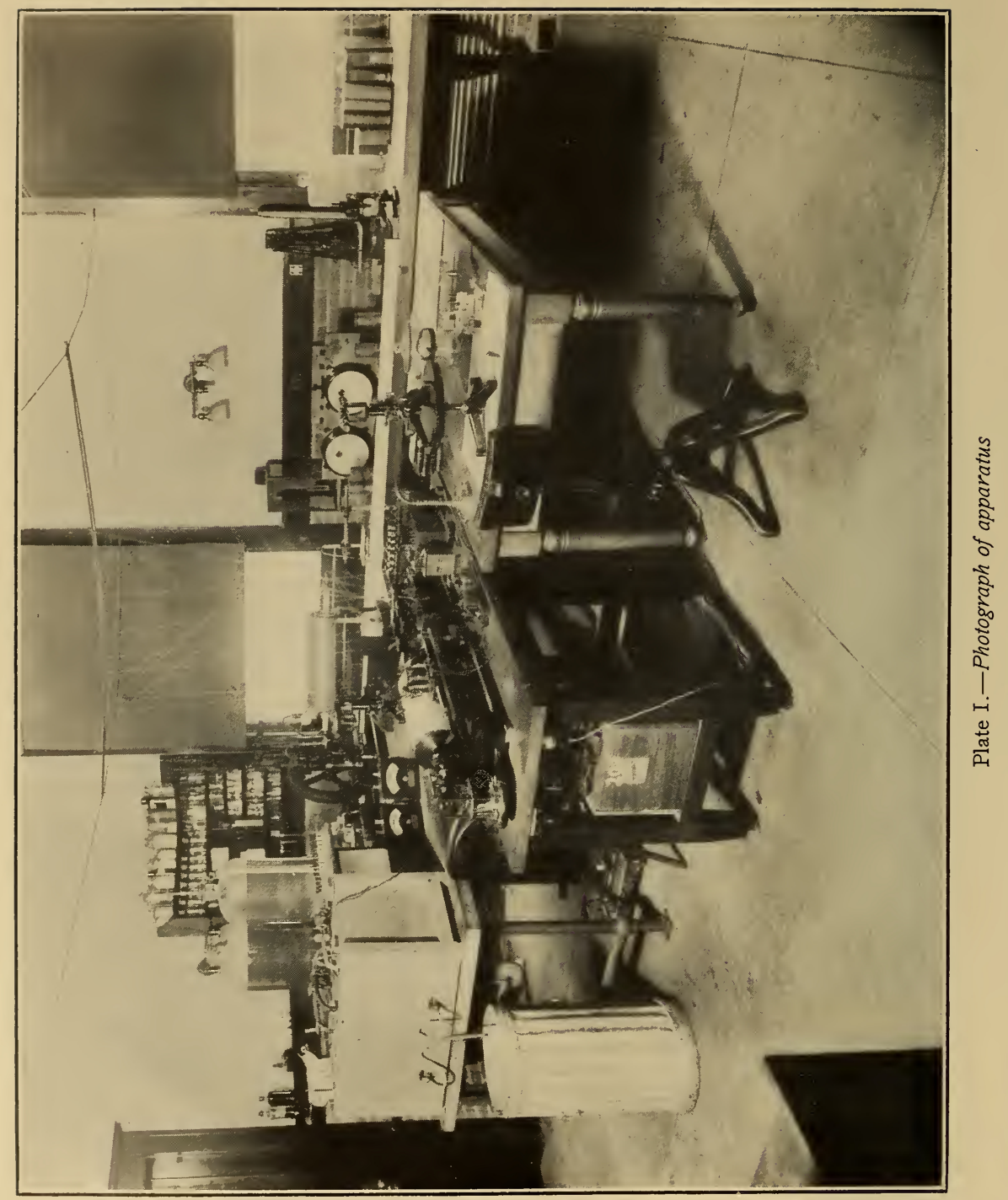

